\title{
SWEDIAUR: THE VICIOUS ANTI-HUNTER RHEUMATO-VENEREOLOGIST
}

\author{
by
}

\author{
MICHAEL KELLY
}

I FIRST read about Swediaur (1748-1824) in Bumstead's American edition of Babington's 1837 English translation of Ricord's French translation of Hunter's 1786 Treatise on Venereal Disease. A chapter entitled 'Gonorrhoeal rheumatism' mentions Swediaur several times; thus:

\begin{abstract}
Hunter has not overlooked the articular rheumatism . . . But to Swediaur is due the credit of recognizing the connection between the cause and the effect, between gonorrhoea and the variety of articular rheumatism which we are about to consider; it is to this author, in a word, that we are indebted for establishing the existence of gonorrhoeal arthritis ... ${ }^{1}$ [This is an error; see Musgrave, , ;]

All authors who have written on venereal diseases since Swediaur have spoken of gonorrhoeal rheumatism, and hence it is necessary for us to supply Hunter's deficiency in this respect. ${ }^{1}$
\end{abstract}

I looked around for references to Swediaur and I was informed that Dorland lists a Swediaur's disease; 4 and a Melbourne library has a two-volume Latin medical glossary published by Swediaur in $1812 .{ }^{5}$ Hirsch's mention of Swediaur's Philosophical Dictionary on the Opinions of Modern Philosophers on Metaphysical, Moral and Political Subjects $1786^{\circ}$ suggests some versatility.

In 1798 Swediaur claimed he had done his first writing on venereal disease in 1770 and his early English editions had been translated into French. ${ }^{7}$ Hirsch says he was of Swedish birth, that he graduated in Vienna and spent twelve years in Edinburgh and London, where he published three editions of Practical Observations on Venereal Complaints and was editor of the Foreign Medical Review which later became the London Medical Journal. In 1789 ill-health sent Swediaur to Paris where he published in French the Traité complet sur les Symptômes, les Effets, la Nature et le Traitement des Maladies Syphilitiques. This was a great success and went to seven French editions, besides several in Italian and English. ${ }^{6}$

It is a shot in the dark, but perhaps a reason for Swediaur's move to Paris was his attack on Hunter's Treatise on Venereal Disease in his 1788 edition. ${ }^{8} \mathrm{I}$ discovered this by accident; $I$ had the book a few months before I realized its chief interest lies in a nineteen-page addendum entitled 'A short review of a late treatise on the venereal disease by John Hunter'. Swediaur was clearly excited by envy of Hunter's great name. It is a great book, says Swediaur, but he 'found several passages which deserved some further notice in order to render young practitioners more cautious not to be deceived by specious and fallacious reasoning, supported by professonial authority ...'

Swediaur believed that Hunter 'sat down with the pen in his hand to prove how many whimsical ideas and monstrous excrescences of his brain an ingenious man may think worthy of the public attention and secondly, how much a vain man, who is 


\section{Swediaur: The Vicious Anti-Hunter Rheumato-venereologist}

ignorant of the different writings and discoveries made by his contemporaries . . . can attribute to himself what he should have attributed to others . . . This, however, must be the case, when a man sits down and writes with the fullest persuasion, that, feeling himself possessed of some genius, all the rest of the profession have none ...'9

Swediaur proceeds by the boring method of quotation in detail of words he disliked followed by refutation-often word by word:

'The balsams, turpentines, dissolved in water'-This . . . is the first instance, I know of, of those substances being soluble in water. ${ }^{10}$

... p. 297. He ... pronounces ulcers not venereal, which the rest of the London surgeons declared to be venereal, and when we come to inquire, why he thought them not venereal, we find it is because it appeared to him so. ${ }^{11}$

p. 300, 301 [two whole pages unquoted] nothing but vague and false conclusions from vague and false premises. ${ }^{11}$

We leave this unintelligible jargon without any comment; but we think the quacks greatly indebted ...Mr. H. appears, in this case, like an acute lawyer, who makes out of one law-suit five, and we have nothing to say but pity the poor client.12

In two places-on Hunter's allowing married men to cohabit with their wives ${ }^{13}$ and on Hunter's views on masturbation ${ }^{14}$-Swediaur's abuse becomes nearly as offensive as possible by mentioning Hunter's marital relations with his wife.

I fear Mr. H. would not trust to make the experiment himself upon his own wife; I certainly would not try it upon mine. 13

... it is the most consummate impudence even to attempt to reason men out of it. But Mr. H. seems to delight in advancing paradoxes, and in employing his mental as well as generative faculties contrary to the laws of Nature, at least he wishes to persuade us so. However, as he is married, and not, as we might expect from the principles laid down above, for the care of his own health, to an ugly beast, but to a very fine amiable woman, this doctrine seems to me nothing more or less but a new kind of puff of highly-refined quackery; and as a practice of the Professor in this place agrees so little with his theory, we hope, for the happiness of his venereal patients, the same will be the case with regard to the manner of treatment of their respective complaints. ${ }^{14}$

After this disgraceful performance Swediaur wrote no more in English; but he still could not contain his vicious envy of Hunter. The preface to the early French editions contains

J'ai ajouté à la troisième édition anglaise une courte critique d'un ouvrage sur la maladie vénérienne par J. Hunter, qui a été traduit en français. L'auteur est mort depuis; et son ouvrage, qui contient plusieurs vérités neuves et utiles, avec une foule d'erreurs et de faux conseilspratiques fondés sur un vague empirisme, étant presque oublié en Angleterre, et n'ayant point été réimprimé, je me crois dispensé d'en parler davantage. ${ }^{15,16}$ [I have added to the third English edition a short criticism of a work on the venereal disease by John Hunter, which has been translated into French. The author has since died; his work which contains many new and useful truths with a wealth of error and false advice, is founded on vague empiricism. It is almost forgotten in England and not having been reprinted I think I need speak of it no more].

I have not discovered when it was that Swediaur could no longer say Hunter's book had not been reprinted.

UNKNOWN PIECE OF HUNTERIANA IN WELL-KNOWN BOOK

I had the 1788 book some time before I read the final chapter, and it was some time 


\section{Michael Kelly}

before I realized it might be important. The first time I tried to read that chapter through I hated Swediaur for his foul abuse; I had expected praise of Hunter and I was nauseated. Thinking that one who made so free with Hunter would have other claims to fame in British medicine, I searched in bibliographies without result. Swediaur disappeared from the British scene and has hardly left a trace. Which is what we should expect from one who wrote so badly and with such venom against a great man.

Swediaur's 1788 New York edition is completely rearranged and printed two Edinburgh pages to one New York page; the anti-Hunter addendum is missing. ${ }^{17}$ I read about this in Austin ${ }^{18}$ and secured the title page, table of contents and rheumatological pages of a copy which once belonged to Nathaniel Stanleys. I asked several British and American historians if they had known about Swediaur's abuse of Hunter and none of them had. Swediaur is best known in America ${ }^{18}$ for an 1815 English translation from the 1804 French edition. ${ }^{19}$ That edition might have been sold in Britain after the defeat of Napoleon and no one would have remembered Swediaur's sins of 1788. For twenty years it would not have been possible for Swediaur to visit Britain.

I was astonished to have found this choice (if foetid) piece of Hunteriana, totally unremarked among the concluding pages of a well-known book which had been advertised by the bookseller as containing 'the author's autograph to Dr. Withering'. I have known no British bookseller to list this book as containing a reference to Hunter; yet an American bookseller (whose price was $60 \%$ above the British) says it has a 'critical review of John Hunter's treatise on the same subject'. There must be many owners of copies of this book who have thought (as I thought until I inquired) that Swediaur's attack on Hunter must be well known. Yet hardly a single British or American medical historian has heard of it; the only comment I can get out of a leading Hunterian is that Swediaur was a cheerful chap who liked controversy. I have not found anywhere else that abusive reference to the opponent's marital relations was an accepted controversial method of the time.

At the time Swediaur wrote the book he was highly satisfied with conditions in Britain. He said treatment was better in London than in any other part of Europe;20 sufferers from venereal disease got more sympathy in the British Isles. It was common, said Swediaur, for British doctors to treat the patients free, or for prosperous people to pay the medical fees of poor patients. Swediaur referred often to Hungarian Professor Winterl, Dr. North of the Great Military Hospital, New York, and to Benjamin Rush.

In the chapter on Hunter there are many misquotations, as there are throughout the book. The introduction to Swediaur's pharmacopoeia syphilitica is prefaced with these four lines from Pope's Essay on Criticism; Swediaur attributes them to Garth's Dispensary:21

So modern 'Pothecaries, taught the art By doctor's bills to play the doctor's part, Bold in the practice of mistaken rules, Prescribe, apply, and call their masters fools. ${ }^{28}$ 


\section{Swediaur: The Vicious Anti-Hunter Rheumato-venereologist}

\section{GONORRHOEAL RHEUMATISM}

It remains now to touch on Swediaur's 'nearly first' in gonorrhoeal arthritis. The 1788 edition $^{23}$ mentions blenorrhagia arthritica in a table; these are the only passages containing reference to muscle or joint pain:

In the bones. Either the most excruciating pains and swellings, commonly called tophi, exostoses, etc. especially troublesome at night when the patient grows warm in bed; an ulceration in their external, or a corruption of their internal substance ... The bones most liable to be affected by this disease, are those which are not covered with muscles ... ${ }^{24}$

Sometimes the venereal poison will produce ... pains in several parts of the body resembling those of the rheumatism; pains in the articulation resembling those of the gout; white swelling; nervous or hectic fevers, consumption of the lungs, or simple emaciation ....25

Flying rheumatic pains, violent head-achs and pain in the hip sometimes originate from this source. The warm bath, with some saline preparation of mercury, with the decoction of the stipites dulcimarae, I have seen cure disorders of this kind . . . ${ }^{96}$

These passages do not describe gonorrhoeal swelling of joints such as we should expect from the passage in Bumstead, nor does Swediaur in his first French edition;27 there is only part of a chapter on wandering pains in tendons and muscles. ${ }^{25}$ The 1804 French edition uses none of this material but has a short chapter containing an accurate description of gonococcal arthritis. Here is something from the 1815 translation; the chapter is headed 'Of Arthrocele, Gonocele, or Blenorrhagic Swelling of the Knee'.

A very considerable swelling of the knee (sometimes of both knees, and the heel at once) attended by excruciating pains in the joint, sometimes occur in men after a blenorrhagia. These pains accompanied by more or less of symptomatic fever, continue for two or three weeks, and gradually go off, leaving a stiffness in the joints, which lasts for many months ... .

It is surprising that no author has treated of this disease as the consequence of a symptom of blenorrhagia. It is not very uncommon, for in the course of my practice I have seen 6 or 8 cases, each of which came on about the eighth or sixth day of the blenorrhagia ...28

\section{SUMMARY}

At the very beginning of his criticism Swediaur wrote ' $\mathrm{Mr}$. Foot in his Observations on the new opinions contained in this treatise has taken them up already in so masterly a manner . . .'29 The well-known criticism of Hunter by Jesse Foot (1744-1824) went to 460 pages. ${ }^{30}$

I do not know why this piece of Hunteriana has not been publicized; it cannot be unknown to the Hunterians.

Swediaur's description of gonorrhoeal arthritis in 1804 may have been the first after that of William Musgrave in 1703.

\section{REFERENCES}

1. Bumstrad, F. J., A Treatise on Venereal Disease by John Hunter, F.R.S., with Copious Additions by Philip Ricord, Philadelphia, Blanchard \& Lea, 2nd ed., 1859, 275-276.

2. Musgrave, W., De Arthritide Symptomatica Dissertatio, Exeter, Yeo \& Bishop, 1703, 292 pp. 


\section{Michael Kelly}

3. Kelly M., 'De Arthritide Symptomatica of William Musgrave (1657-1721): His description of neuropathic arthritis', Bull. Hist. Med., 1963, 37, 372-378.

4. Dorland's Illustrated Medical Dictionary, Philadelphia, Saunders, 6th ed., 1965. pp. 436, 1479.

5. Swediaur, F., Iatrike, seu Novum Medicinae Systema, 2 vols., Paris, Gabon, 1812.

6. HIRSCH, G., Bibliographisches Lexikon der hervorragenden Arzte aller Zeiten und Volker, Munchen, Haberling \& Co., 3rd ed., 1962, 5, 178-179.

7. Swediaur, F., Traité Complet sur les Symptomes, les Effets, la Nature et le Traitement des Maladies Syphilitiques, Paris, Mequignon, 1798, pp. i, iii.

8. Idem., Practical Observations on Venereal Complaints, third ed. corrected and enlarged, To which are added, An Account of a New Venereal Disease which lately appeared in Canada; and a Pharmacopoeia Syphilitica, Edinburgh, Elliot, Kay \& Co., 1788, pp. $297-315$.

9. Ibid., p. 298.

10. Ibid., p. 303.

11. Ibid., p. 306.

12. Ibid., p. 310.

13. Ibid., p. 300 .

14. Ibid., p. 315.

15. SWEDIAUR, Traité complet ...., 1798, p. ix.

16. Ibid., quatrième ed. 1801 , p. xvii.

17. Swediaur, F., Practical Observations on Venereal Complaints, New York, S. Campbell, 3rd ed., 1788, 128 pp.

18. AustIN, R. B., Early American Medical Imprints, Washington, Department of Health, 1961, p. 194.

19. SwediaUr, F., A Complete Treatise on the Symptoms, Effects, Nature and Treatment of Syphilis, translated from the fourth French edition by Thomas T. Hewson, Philadelphia, Thomas Dobson, 1815, 539 pp.

20. Idem., Practical Observations on Venereal Complaints, Edinburgh, 1788, p. 19.

21. Ibid., p. 265.

22. PoPe, A., Essay on Criticism, lines 108-111, The Poetical Works of Alexander Pope, edited by W. M. Rossetti, London, Ward, Lock \& Bowden, [n.d.], p. 10.

23. Swediaur, F., Practical Observations on Venereal Complaints, Edinburgh, 1788, p. 71 ; New York ed., 1788, p. 34.

24. Ibid., p. 159, (New York ed., p. 76).

25. Ibid., p. 160 .

26. Ibid., pp. 241-242, (New York ed., p. 125).

27. Swediaur, F., Traité complet . . . . , Paris, 1798, 2, pp. 107-115.

28. Idem., A complete Treatise on the Symptoms, Effects, Nature and Treatment of Syphilis, Philadelphia, 1815, pp. 108-109.

29. Idem., Practical Observations on Venereal Complaints, Edinburgh, 1788, p. 397.

30. Foot, J., Observations upon the New Opinions of John Hunter on the Venereal Disease, London, Becket, parts 1 \& 2, 1786, part 3, 1787 (Index-Catalogue of Surgeon-General's Library). 